\title{
Stillbirth in Nigeria: Rates and Risk Factors Based on 2013 Nigeria DHS
}

\author{
Tukur Dahiru*, Alhaji A. Aliyu \\ Department of Community Medicine, Ahmadu Bello University, Zaria, Nigeria \\ Email: "tukurdahiru2012@gmail.com
}

Received 17 May 2016; accepted 7 August 2016; published 10 August 2016

Copyright (C) 2016 by authors and OALib.

This work is licensed under the Creative Commons Attribution International License (CC BY).

http://creativecommons.org/licenses/by/4.0/

(c) (i) Open Access

\section{Abstract}

Introduction: Stillbirth remains a public health problem with an estimate of 2.6 million stillbirths in 2015 of which $98 \%$ occurred in low- and middle-income countries and over three-quarters of these occurring in Sub-Saharan Africa (SSA) and south Asia. Further, only ten countries carry the burden of over $65 \%$ of total stillbirths in the world including Nigeria in the second position. The objective of this analysis is to estimate stillbirth rates and identify the determinants of stillbirth in Nigeria using the 2013 Nigeria DHS data. Methods: The study utilized the nationally-representative sample of women of reproductive age interviewed during the 2013 Nigeria DHS. Analysis was restricted to 31,671 women aged 15 - 49 years who had a pregnancy reaching at least seven months of gestation in the five-year period prior to the survey. Descriptive statistics and regression analysis were performed using Stata v13 to determine significant factors related to stillbirth. Incidence Risk Ratio (IRR) was used to assess strength of association between independent and dependent variables. Results: Overall stillbirth rate is 12.5 per 1000 pregnancies, with rates as high as 22 per 1000 (among women aged 15 - 19 years) and as low as 6.4 per 1000 (among women who received skilled ANC). Age, household wealth, higher birth order, facility delivery, Caesarean delivery, rural residence and ever use of contraceptive are consistent determinants of stillbirth in both the bivariate and multivariate models. Women in rich households have lower IRR of stillbirth $0.60 ; 95 \%$ CI: $0.45-0.59$ ) as well as women who had ever used modern contraception (IRR $=0.72 ; 95 \%$ CI: 0.63 - 0.81). However, health facility deliveries as well as deliveries through a C-section, rural residence and age older than 20 years all carry increased risk of stillbirth (IRR $=1.81 ; 95 \%$ CI: 1.05 1.33), (IRR = 2.46; 95\% CI: 2.03 - 2.98), (IRR = 1.41; 95\% CI: $1.24-1.59)$, and (IRR = 2.23; 95\% CI: $1.75-2.59)$ respectively. Conclusions: The study revealed that there are several factors responsible for stillbirth in Nigeria. Age, household wealth, higher birth order, facility delivery, Caesarean delivery, rural residence and ever use of contraceptive are consistent determinants of stillbirth in both the bivariate and multivariate models. There is urgent need by the National government to improve quality of maternal health care services and interventions to improve utilization and quality of prenatal care.

${ }^{*}$ Corresponding author. 


\title{
Keywords
}

\author{
Stillbirth, Determinants, Rates, Nigeria
}

\author{
Subject Areas: Public Health
}

\section{Introduction}

Worldwide, it was estimated that in 2015 there were 2.6 million third trimester stillbirths (SB) of which $98 \%$ occurred in low- and middle-income countries and over three-quarters of these occurring in Sub-Saharan Africa (SSA) and south Asia [1]. It is also estimated that only ten countries carry the burden of over $65 \%$ of total stillbirths in the world; Nigeria being ranked in the second position with an estimated 313,700 stillbirths (SB) in 2015 [1].

While significant progress was made during the Millennium era in reducing child and maternal mortality, the progress made in reducing stillbirth is the slowest; an annual Average Rate of Reduction (ARR) of $2.0 \%$ in comparison to AAR of 3.0\% for maternal death or 3.1\% for neonatal death [2] [3]. This arose partly from overall neglect of the problem such as poor investment in terms of overseas development assistance that characterized child and maternal health agenda, invisibility of the health problem at both the global and national health agenda despite existence of cost-effective interventions to end preventable stillbirths [4]. However, following the Lancet Series of 2011 and Every Newborn Action Plan (ENAP) of 2014, the issue of stillbirth assumed international health agenda with increased visibility both at national and international health fora [4] [5]. Following these international commitments, a target was set to reduce global (as well as at country level) stillbirth rate of 12 or fewer stillbirths per 1000 births by 2030 from 25 stillbirths per 1000births in 2000. Of the 2.6 million stillbirths estimated to have occurred in 2015, about half, 1.3 million occurred during child birth underscoring the urgent need to provide skilled assistance during this critical period; about $60 \%$ of global stillbirths occurred in rural areas [1].

Risk factors for stillbirths (SB) can broadly be classified into three: maternal, fetal and contextual. Maternal factors include older and younger maternal age; short pregnancy interval, maternal infections (syphilis, malaria in pregnancy), maternal obesity and malnutrition, cigarette smoking, alcohol and drug abuse, maternal disease (pre-eclampsia and eclampsia), previous stillbirth, primiparity and multiparity; fetal factors include male sex, prematurity, extremes of birth weight; while contextual factors include lack of Access to Antenatal Care (ANC), lack of skilled care during child birth, rural residence, low socioeconomic status, type of marriage, ethnicity, poor maternal education and environmental pollution particularly indoor air pollution [1] [6] [7].

In the Nigerian context, stillbirth is a public health problem where an estimated 313,700 occurred in 2015 making Nigeria the second largest contributor of stillbirths worldwide (12\% of the global burden of stillbirth) or $30 \%$ of total stillbirths in sub-Saharan Africa. This figure translates to a stillbirth rate of 42.9 per 1000 births. There was an estimated 278,000 stillbirths in 2000 equivalent to a stillbirth rate of 52.3 per 1000, implying an average annual rate of reduction of $1.3 \%$ [8]. However, from fragmentary and hospital-based studies, the stillbirth rates as high as 85 per 1000 births have been reported [9]. While Fawole (2011) reported a relatively lower figure of 71 per 1000 births [10]. Though, these studies provide insights into the levels, possible trends and associated factors, they are limited to the areas/hospitals where they have been conducted. Thus, there is a need to estimate a nationally-representative figure with large sample size and more recent data; this was accomplished in the 2013 Nigeria Demographic and Healthy Survey [11]. Still, the DHS final report only provided trends in stillbirth rates against some background socio-demographic characteristics; it is therefore pertinent that a further analysis of the determinants be carried for programming and policy formulation.

\section{Methods}

The study utilized the 2013 Nigeria DHS data sets. The survey was a three-stage stratified cluster sampling design. The clusters are adopted from the 2006 Nigeria census in which they are synonymous with Enumeration Areas (EAs). The EAs provided the primary sampling units for the both the census and the 2013 Nigeria DHS. During this survey, a total of 904 clusters were sampled of which 372 were in urban areas and 532 in rural areas. 
A representative sample of 40,680 households was sampled for the survey allowing a minimum of 943 completed interviews in each state of the 36 states of the country and 45 households in each cluster. A de jure population of all women aged 15 - 49 years and a de jure population of men aged 15 - 49 years were eligible for the interview. The survey used basically three types of structured questionnaires on the respondents: the household questionnaire, woman's questionnaire and man's questionnaire. For this investigation, we are interested in the woman's questionnaire since we are interested in the pregnancy outcome associated with each that was pregnant five years before the survey. The questionnaire collected information on background characteristics, reproductive history and childhood mortality, family planning methods, fertility preferences, antenatal, delivery, pregnancy outcome and postnatal care and host of other health issues relating to specific diseases and diseaseprevention programmes/interventions [NPC 2014]. Our analysis was restricted to all pregnancies of at least seven months or more duration not ending in live birth within the five-year period prior to the survey in 2013. The study used definition of stillbirths by World Health Organization (WHO) as late fetal deaths weighing at least 1000 grams or occurring at or beyond 28 weeks of gestation. However, because gestational age criterion is more feasible in an epidemiological survey like DHS since it is a better predictor of maturity and viability than birth weight which is equally adopted here [1] [8] [12].

\subsection{Variables and Definitions in the Analysis}

The variables of interest in this study are broadly divided into two: dependent (or outcome) and independent (or explanatory) variable. These variables with their operational definitions and coding are shown in Table 1 . The dependent variable is the stillbirth which is defined as an infant born without any signs of life (i.e. without crying, breathing, or movement at the time of birth) at 28 weeks of gestation or later [13]. The independent or explanatory are listed above with their operational definitions. These variables were selected based on review of empirical research [6]-[8] [13].

\subsection{Data Analysis}

Descriptive statistics were generated across background socio-demographic. Numbers of pregnancies of at least seven months gestation or 28 weeks gestation and stillbirths were generated with subsequent estimation of stillbirth rates by background characteristics.

The statistical model for assessing the strengths of some selected risk factors in stillbirths is the Poisson regression since the assumption here is that the distribution of stillbirths in the general population follows a binomial distribution (each pregnancy has a binary outcome; live birth or a stillbirth) and that stillbirth in general population is a rare event. In the 2013 Nigeria DHS there were 396 stillbirths in 31,671 pregnancies of at least seven months (or 28 weeks). Furthermore, prevalence data in a cross-sectional study follows a binomial distribution [Barros and Hirakata, 2003].

\subsection{Statistical Model}

The Poisson regression model is represented by:

$$
\log \left(\frac{n}{t}\right)=\beta_{0}+\beta_{1} \mathrm{X}_{1}+\cdots+\beta_{k} \mathrm{X}_{k}
$$

where $n$ is the count of events for a given individual, $t$ the time it was followed-up, and $X$ the covariates. The model parameters $\left(\beta_{i}\right)$ are log relative risks. Following the recommendation of Barros and Hirakata (2003), we adopted the Poisson regression adjusted by deviance. The analysis was carried using Stata v13.

Ethical statement: This study is a secondary analysis of the 2013 NDHS, so does not require ethical approval. We were 2015 DHS Fellows, we registered and requested for access to NDHS datasets from DHS on-line archive and received approval to access and download the de-identified DHS data files.

\section{Results}

In the 2013 Nigeria DHS there were 396 stillbirths in 31,671 pregnancies of at least seven months (or 28 weeks) to derive a stillbirth rate of 12.5 per 1000 pregnancies. The number of stillbirths, pregnancies of seven months duration and stillbirth rates against some selected socio-demographic characteristics is shown in Table 2. There 
Table 1. List of variables, variable definition and variable coding.

\begin{tabular}{|c|c|c|c|}
\hline S/No & Variable & Variable definition & Coding \\
\hline \multicolumn{4}{|c|}{ Main outcome variable } \\
\hline 1 & Still birth & $\begin{array}{l}\text { Death of fetus after } 28 \text { weeks gestation } \\
\quad \text { (or seven months and above) }\end{array}$ & Died (1); live birth (0) \\
\hline \multicolumn{4}{|c|}{ Main explanatory variables } \\
\hline 2 & Maternal age & Maternal age at the time of interview & Numerical values in years \\
\hline 3 & Maternal education & $\begin{array}{l}\text { Highest level of formal education } \\
\text { attained by mother }\end{array}$ & $\begin{array}{l}\text { None (0); primary (1); secondary (2); } \\
\text { tertiary (3) }\end{array}$ \\
\hline 4 & Ethnicity & Ethnic affiliation of the respondent & $\begin{array}{l}\text { Hausa (1); Yoruba (2); Igbo (3); } \\
\text { Fulani (4); Others (5) }\end{array}$ \\
\hline 5 & Place of residence & Place of residence either rural or urban & Urban (1); rural (2) \\
\hline 6 & Household wealth index & Measure of household wealth in quintiles & Poor (1); middle (2): rich (3) \\
\hline 7 & Religion & Religious affiliation of mother & Christianity (1); Islam (2) Traditional/Others (3) \\
\hline 8 & Region of residence & Geopolitical zone of residence & South (1); North (2) \\
\hline 9 & Birth weight & Birth in kilograms (for facility deliveries) & $<2.5 \mathrm{Kg}(1) ; 2.5-4.5 \mathrm{Kg}(2) ;>4.5$ (3) \\
\hline 10 & Complications & Informed of pregnancy complications & None (0); Yes (1) \\
\hline 11 & Birth order & Birth order of children born & $\begin{array}{l}\text { First; second; third; fourth; } \\
\text { fifth and sixth and more }\end{array}$ \\
\hline 12 & Pregnancy desire & If the last pregnancy was desired & Wanted (1); Mistimed (2); Unwanted (3) \\
\hline 13 & Place of delivery & Place where delivery took place & Home (0); Health facility (1) \\
\hline 14 & Type of energy source & Source of energy for household use & Solid (1); Non-solid fuels (0) \\
\hline 15 & Obesity & $\begin{array}{l}\text { Measure of body fastness using } \\
\text { body mass index (BMI) }\end{array}$ & Underweight (1); Normal (2); Obese (3) \\
\hline 16 & Delivery mode & How fetus was delivered & Normal (0); Caesarean section (1) \\
\hline 17 & Use of ANC & Number of ANC visits & No ANC use (0); At least one ANC (1) \\
\hline 18 & Skilled ANC use & $\begin{array}{l}\text { If person seen during ANC } \\
\text { visit is skilled or not }\end{array}$ & Skilled ANC (1); None-skilled ANC (0) \\
\hline
\end{tabular}

are clear differentials in stillbirth rates by some background characteristics. Stillbirth rates are highest among the youngest and oldest women, 22 and 19 respectively compared to middle age groups of 20 - 39 years. Similarly, stillbirth rate is highest among women in poor households. It is also highest among the first births or first pregnancies so also with primiparity. Obese women have highest rates of SB than normal or underweight.

Table 3 show the result of Poisson regression adjusted by deviance model of stillbirth and some selected background characteristics. Incidence Rate Ratio (IRR) is the measure of the association between these background characteristics and occurrence of stillbirths. Two models were generated: univariate and multivariable. In the univariate model, maternal age, maternal level of education, household wealth index, birth order, facilitybased delivery, indoor air pollution from solid fuels, Caesarean section, rural residence and ever use of contraception significantly predicts stillbirth. Unexpected results include increased risk of stillbirth with prenatal care, sex of baby and multiple gestations; though these relationships are not significant.

Generally, when the multivariable model was generated, most of these variables retained their significant relationships with SB. Virtually all the factors entered in the model are significantly associated with risk of stillbirth. Maternal age is significantly associated with risk of stillbirth; women in age bracket of 35 - 49 years have 
Table 2. Number of stillbirths, pregnancies of seven months and stillbirth rates for the five-year period preceding the survey, by background characteristics, Nigeria 2013.

\begin{tabular}{|c|c|c|c|}
\hline Background characteristics & Stillbirths & Pregnancy 7 months+ & Stillbirth rate \\
\hline \multicolumn{4}{|l|}{ Age } \\
\hline $15-19$ & 36 & 1620 & 22.0 \\
\hline $20-29$ & 164 & 15,078 & 10.9 \\
\hline $30-39$ & 123 & 11,776 & 10.4 \\
\hline $40-49$ & 61 & 3196 & 19.1 \\
\hline \multicolumn{4}{|l|}{ Maternal education } \\
\hline No formal education & 190 & 15,611 & 12.2 \\
\hline Primary & 88 & 6086 & 14.4 \\
\hline Secondary or higher & 106 & 9974 & 10.6 \\
\hline \multicolumn{4}{|l|}{ Husband education } \\
\hline No formal education & 155 & 12,597 & 12.3 \\
\hline Primary & 65 & 5829 & 11.2 \\
\hline Secondary or higher & 158 & 12,743 & 12.4 \\
\hline \multicolumn{4}{|l|}{ Household wealth } \\
\hline Poor & 215 & 14,847 & 14.5 \\
\hline Middle & 56 & 5941 & 9.4 \\
\hline Rich & 112 & 10,882 & 10.3 \\
\hline \multicolumn{4}{|l|}{ Occupational status of mother } \\
\hline Has occupation & 270 & 9450 & 12.0 \\
\hline No occupation & 113 & 22,221 & 12.2 \\
\hline \multicolumn{4}{|l|}{ Religion } \\
\hline Christianity & 130 & 11,548 & 11.3 \\
\hline Islam & 250 & 19,638 & 12.8 \\
\hline Traditional & 3 & 485 & 6.2 \\
\hline \multicolumn{4}{|l|}{ Birth order } \\
\hline $1^{\mathrm{st}}$ & 66 & 3738 & 17.8 \\
\hline $2^{\text {nd }} \& 3^{\text {rd }}$ & 102 & 10,762 & 9.4 \\
\hline $4^{\text {th }} \& 5^{\text {th }}$ & 67 & 8061 & 8.4 \\
\hline $6^{\text {th }} \&$ more & 92 & 9051 & 10.1 \\
\hline \multicolumn{4}{|l|}{ ANC use } \\
\hline $1+$ visit & 78 & 12,369 & 6.3 \\
\hline None & 133 & 19,118 & 6.9 \\
\hline \multicolumn{4}{|l|}{ Skilled ANC } \\
\hline Yes & 81 & 12,678 & 6.4 \\
\hline No & 129 & 18,702 & 6.9 \\
\hline \multicolumn{4}{|l|}{ Focused ANC } \\
\hline No ANC & 70 & 10,957 & 6.4 \\
\hline 1 - 3 visits & 28 & 3977 & 6.9 \\
\hline $4+$ visits & 109 & 15,731 & 7.0 \\
\hline \multicolumn{4}{|l|}{ Initiation of ANC } \\
\hline Early & 41 & 5326 & 7.7 \\
\hline Intermediate & 84 & 12,640 & 6.6 \\
\hline Late & 16 & 2564 & 6.3 \\
\hline
\end{tabular}




\section{Continued}

$\begin{array}{cccc}\text { Parity } & & & \\ 1 & 66 & 3738 & 17.8 \\ 2-4 & 140 & 15,233 & 9.2 \\ 5+ & 120 & 12,640 & 9.5\end{array}$

\section{Energy source (IAP)}

Solid fuel

Non-solid fuel

\section{Ethnicity}

Hausa

Yoruba

Igbo

Fulani

Others

\section{BMI}

Underweight

Normal

Obese

\section{Birth interval}

$>24$ months

$<24$ months
68

315

5787

25,883

11,205

3475

3540

2618

10,833

2653

26,494

2524

316

41

325

58
25,031

6640
9.9

11.8

12.2

13.6

12.3

8.0

13.6

11.5

16.3

13.0

8.8

Table 3. Number of stillbirths and pregnancies of seven months and stillbirth rate for the five-year period preceding the survey, by background characteristics, Nigeria 2013.

\begin{tabular}{|c|c|c|}
\hline \multirow{2}{*}{ Background characteristics } & Univariate & Multivariate \\
\hline & IRR (95\% CI) & IRR (95\% CI) \\
\hline \multicolumn{3}{|l|}{ Age } \\
\hline $15-19$ & 1.00 & 1.00 \\
\hline $20-34$ & $1.49(1.06-1.57)^{* * *}$ & $2.23(1.75-2.59)^{* * *}$ \\
\hline $35-49$ & $1.29(1.06-1.57)^{* *}$ & $2.35(1.87-2.96)^{* * *}$ \\
\hline \multicolumn{3}{|l|}{ Maternal education } \\
\hline Noformal education & 1.00 & 1.00 \\
\hline Primary & $1.13(1.03-1.22)^{* *}$ & $1.58(1.41-1.78)^{* * *}$ \\
\hline Secondary or higher & $0.73(0.67-0.80)^{* * *}$ & $0.98(0.84-1.14)$ \\
\hline \multicolumn{3}{|l|}{ Household wealth } \\
\hline Poor & 1.00 & 1.00 \\
\hline Middle & $0.64(0.57-0.70)^{* * *}$ & $0.52(0.45-0.59)^{* * *}$ \\
\hline Rich & $0.63(0.59-0.69)^{* * *}$ & $0.60(0.51-0.70)^{* * *}$ \\
\hline \multicolumn{3}{|l|}{ Ethnicity } \\
\hline Hausa & 1.00 & 1.00 \\
\hline Yoruba & $0.74(0.66-0.83)^{* * *}$ & $0.78(0.65-0.94)^{*}$ \\
\hline Igbo & $0.52(0.45-0.60)^{* * *}$ & $0.74(0.62-0.89)^{* *}$ \\
\hline Fulani & $1.00(0.88-1.14)$ & $1.05(0.91-1.22)$ \\
\hline Others & $0.76(0.70-0.83)^{* * *}$ & $0.81(0.72-0.90)^{* * *}$ \\
\hline
\end{tabular}




\section{Continued}

\section{Birth order}

$1^{\text {st }}$

$2^{\text {nd }} \& 3^{\text {rd }}$

$4^{\text {th }} \& 5^{\text {th }}$

$6^{\text {th }} \&$ more

ANC visits

None

1 - 3 visits

4+ visits

Place of delivery

Home

Facility (public \& private)

\section{Pregnancy desire}

Wanted

Mistimed

Unwanted

\section{Energy source (IAP)}

Non-solid fuel

Solid fuel

\section{BMI}

Normal

Underweight

Overweight

Obese

Mode of delivery

Normal (vaginal)

CS

Place of residence

Urban

Rural

Ever use contraception

No

Yes

\section{Sex of baby}

Female

Male

\section{Pregnancy type}

Singleton

Multiple
1.00

$0.84(0.76-0.93)^{* *}$

$0.65(0.58-0.73)^{* * *}$

$0.74(0.67-0.82)^{* * *}$

1.00

$1.12(0.98-1.28)$

1.05 (0.96 - 1.15)

1.00

$1.27(1.18-1.37)^{* * *}$

1.00

$0.57(0.67-0.70)^{* * *}$

$0.94(0.71-1.26)$

1.00

$1.21(1.10-1.32)^{* * *}$

1.00

$0.71(0.62-0.83)^{* * *}$

$0.78(0.71-0.86)^{* * *}$

$0.99(0.89-1.11)$

100

$2.44(2.03-2.92)^{* * *}$

1.00

$1.38(1.28-1.49)^{* * *}$

1.00

$0.69(0.63-0.75)^{* * *}$

1.00

1.05 (0.98 - 1.13)

1.00

$0.99(0.77-1.26)$
1.00

$0.63(0.54-0.68)^{* * *}$

$0.42(0.36-0.48)^{* * *}$

$0.50(0.43-0.58)^{* * *}$

1.00

$1.33(1.16-1.53)^{* * *}$

$1.44(1.28-1.61)^{* * *}$

1.00

$1.81(1.05-1.33)^{* *}$

1.00

$0.62(0.50-0.75)^{* * *}$

$1.16(0.86-1.56)$

1.00

$0.84(0.71-0.98)^{* *}$

1.00

$0.64(0.54-0.76)^{* * *}$

$0.79(0.69-0.90)^{* * *}$

$1.42(1.23-1.63)^{* * *}$

1.00

$2.46(2.03-2.98)^{* * *}$

1.00

$1.41(1.24-1.59)^{* * *}$

1.00

$0.72(0.63-0.81)^{* * *}$

1.00

$0.92(0.84-0.99)^{* *}$

1.00

$0.59(0.40-0.88)^{*}$

${ }^{*} \mathrm{p}<0.05 ;{ }^{* *} \mathrm{p}<0.001 ;{ }^{* * *} \mathrm{p}<0.0001$. 
the highest risk of experiencing stillbirth compared to 20 - 34 age group. Women in rich households are at reduced risk of stillbirth than those from poor households (IRR $=0.60$; 95\% CI: $0.51-0.70$ ). The first child carries a significant risk of being born dead compared to subsequent children; the fourth and the fifth children have the lowest risk (IRR $=0.42$; 95\% CI: 0.6 - 0.48). Women from the ethnic groups of Yoruba, Igbo and those belonging to other ethnicity have reduced risk compared to women from Hausa ethnic extraction; in comparison, the Fulanis have increased risk but not significant. Outcome of pregnancy seemed to be not uniform with regards to desirability of the pregnancy; mistimed pregnancies have significantly reduced risk of stillbirths (IRR $=0.62$; $95 \%$ CI: 0.50 - 0.75); while unwanted pregnancies have increased risk even though this is not significant (IRR $=1.16$; 95\% CI: 0.86 - 1.56). Women that delivered in a health facility (either public or private) unexpectedly have increased incidence of stillbirth (IRR $=1.81 ; 95 \%$ CI: 1.05 - 1.33) as well as those that were delivered via a Caesarean section (IRR = 2.46; 95\% CI: 2.03 - 2.98). Expectedly, obese women are at increased risk of stillbirth (IRR = 1.42; 95\% CI: 1.23 - 1.63), but underweight and overweight both have reduced risks of stillbirths. Rural residence increases the incidence of stillbirth while ever use of contraception decreases the incidence. Other unexpected results in this analysis include the increased incidence of stillbirths among those that had prenatal care, female babies; and reduced risks of SBs among babies whose source of energy is solid fuels as well as multiple pregnancies (twins and triplets) (IRR $=0.59$; 95\% CI: 0.40 - 0.88).

\section{Discussion}

We analyzed the most recent DHS data for Nigeria (the 2013 NDHS) and came with a list of risk factors that determine the occurrence of stillbirth as well as rates of SB by socio-demographic characteristics. Until recently, stillbirth has largely remained outside the international health agenda; it is now included in the ENAP (The Every Newborn Action Plan) and part of the Sustainable Development Goals (SDG 3) [8]. The ENAP has set a national target of SB rates of 12 or less per 1000 births by 2030 [14]. Currently, as at end of 2015, Nigeria contributes around $12 \%$ (or 314,000 stillbirths) of global burden of stillbirth second only to India and in terms of stillbirth rates, Nigeria is second to Pakistan with an estimated stillbirth rate of 42.9 per 1000 births [15]. Our figure obtained herein, is at variance with that generated by The Lancet Stillbirth Epidemiology Investigator Group [8] probably due to the fact that the figure generated by the Group is based on modeling using data mostly derived from hospital-based studies that are plagued by selection bias. Estimates from hospital-based studies are very likely to be inflated because majority of these pregnancies are usually difficult ones referred for further management in those referral centers; since four of the seven studies whose estimates were used for modeling stillbirths in Nigeria are in the teaching hospitals which are the highest referral centers in Nigeria. In fact, Adimora reported an estimate of stillbirth rate of 68per 1000 births [16]. Secondly, the stillbirth rate in these hospital-based studies was based on total deliveries and not based on total pregnancies of at least 7 months of gestation (or 28 weeks). This led to contraction in the denominator thereby proportionally inflating the stillbirth rate.

Generally, our regression analysis revealed some risk factors to be strongly associated with SBs as has been reported in the literature: advanced maternal age (greater than 35 years); low or lack of maternal education; socio-economic disadvantage; antenatal care utilization; ethnic minority; pregnancy desire; place of delivery; type of delivery; indoor air pollution from solid fuels; rural residence; maternal obesity; use of contraception; sex of baby and type of pregnancy [6]. According to Aminu et al., these risk factors could broadly be classified into four: maternal; fetal; health system and socioeconomic [6].

Increasing maternal age has been associated with increased risk of stillbirth which is consistent our analysis. An estimated $6.7 \%$ of stillbirths are attributed to older maternal age of more than 35 years [1]. Though, we did not estimate the amount of stillbirths attributed to advanced maternal age, up to $32 \%$ of stillbirths in this study was among women aged 35 years or more. We are unable to demonstrate the dose-response relationship between maternal death and increasing risk of stillbirth that has been demonstrated by previous researchers [17]. A set of factors related to health system and socioeconomic situations are interrelated to increase risk of stillbirths. These factors include maternal education, household wealth level, utilization of prenatal care, place of delivery and place of residence. These factors interact in a complex and synergistic pathways to influence risk of SBs. For instance, socioeconomic disadvantage is associated with deprivation of maternal education which in turn is associated with lack of utilization of antenatal care either because of financial barrier or geographical access due to rural location of the woman. Maternal education, household wealth level and place of residence (urban/rural) are well-documented determinants of prenatal care and facility delivery (Simkhada 2009; Fatusi 2009) [18] [19]. 
Lack or poor maternal education, rural location and poor household wealth level are underlying factors of general well-being of the woman and their effects with regard to stillbirth is through the pathway of restricting utilization of maternal health care including antenatal care, family planning services and emergency obstetric care including caesarean section resulting in high rates (of stillbirth rates) [20]. It is noted that stillbirth rates can be very high even in developed nations [21]; and the three delays model developed for maternal death is also relevant in this context [22]. These delays include: delay in recognizing danger sign; seeking care due to social or economic barriers, or distance and lack of transport; and receiving high quality health care [23].

In the context of our results, we observed that health system factors (utilization of antenatal care and facility delivery) have generated results that are at variance to what has been reported in literature. The literature is replete with reports establishing the relationship between lack of antenatal care, facility delivery and increasing risk of stillbirth [24]-[28]. In this study, use of antenatal care is associated with increased risk of stillbirth displaying a dose-response relationship meaning that with increasing number of ANC visits the IRR increases (Table 3). Similar association is observed with regard to facility delivery; about half (51\%) of women had at least four ANC visits in Nigeria according to 2013 NDHS while one-third (36\%) delivered in a health facility. The association between ANC and increased risk of stillbirth could be that women who attended ANC did so simply because they suspected the pregnancy was not normal, difficult or that they were experiencing some challenges with it and therefore to avoid adverse outcome had to attend antenatal care many times. And if in such situations the challenge or difficulty was not counteracted then the relationship between intervention and outcome may be misinterpreted. This same argument can be made for facility delivery; where women used the facility for delivery as last option in order to save the pregnancy from difficult labour or problem about the fetus. This is purely the case of selection bias among the women; they utilized ANC and facility delivery because their pregnancies had problems $a b$ initio. The second reason likely to explain this reversed association between ANC, FBD and risk of SB has to do with measurement error. The instrument (that is, the questionnaire)used to collect the relevant information might not have captured the variable precisely or it may be due to the inability of the data collectors to accurately and precisely measure the quantity and quality of intervention received [28].

Other factors strongly associated with stillbirth are body mass index of the woman, CS delivery, indoor air pollution, ever use of modern contraception, sex of baby and type of pregnancy. Maternal obesity has been shown to increase the risk of stillbirth; the higher the body mass index the greater the chance of SB. In a metaanalysis conducted by Metwally et al. [29], women with BMI $\geq 30$ were at increased risk of miscarriage (SB) compared to women with normal BMI [OR $=1.89$; 95\% CI: 1.14 - 3.13]. It is postulated that an unfavorable hormonal characteristic of maternal obesity as well as chronic inflammation from excess adipose tissue might be the underlying mechanism of action [30]. Furthermore, it has been demonstrated from observational data, that weight reduction is associated with reduced stillbirth rate in general population [31]. In our analysis, the relationship between maternal obesity and stillbirth hold true only with respect to those who are obese (BMI $\geq 30$ ); for underweight women, the risk is less compared to normal-weight women.

\section{Conclusion}

We conclude discussion by making some notes on the negative findings from our model. Previous literatures have reported the increased risk of SB associated with male babies [32] [33] and multiple pregnancies (twins, triplets or more) [34]. Generally, male babies have $10 \%$ additional risk of stillbirth which could probably be attributed to X-linked congenital conditions, increased risk of preterm labour, and poor fetal growth for male babies [35]. However, in both situations, our model did not show an increased risk of SB with male babies or multiple pregnancies; in fact, in both cases we see a reversed statistically significant association between these factors and stillbirth; male babies and multiple pregnancies have lower risk of ending in stillbirths compared to female babies and singleton babies. Our result speaks to that of Feresu where the risk of SB is not statistically different between male and female babies [36].

\section{References}

[1] Lawn, J.E., Blencowe, H., Waiswa, P., Amouzou, A., Mathers, C., Hogan, D., et al., for The Lancet Ending Preventable Stillbirths Series Study Group with The Lancet Ending Preventable Stillbirths Series Advisory Group (2016) Stillbirths: Ending Preventable Deaths by 2030. Lancet, 387, 587-603. http://dx.doi.org/10.1016/S0140-6736(15)00837-5

[2] WHO, UNICEF, UNFPA, World Bank Group, UN Population Division (2016) Trends in Maternal Mortality: 1990 to 


\section{5. http://apps.who.int/iris/bitstream/10665/194254/1/9789241565141_eng.pdf?ua=1}

[3] You, D., Hug, L., Ejdemyr, S., et al. (2015) Global, Regional, and National Levels and Trends in Under-5 Mortality between 1990 and 2015, with Scenario-Based Projections to 2030: A Systematic Analysis by the UN Inter-Agency Group for Child Mortality Estimation. Lancet, 386, 2275-2286. http://dx.doi.org/10.1016/S0140-6736(15)00120-8

[4] Lawn, J.E., Blencowe, H., Pattinson, R., et al., and the Lancet’s Stillbirths Series Steering Committee (2011) Stillbirths: Where? When? Why? How to Make the Data Count? Lancet, 377, 1448-1463. http://dx.doi.org/10.1016/S0140-6736(10)62187-3

[5] UNICEF, WHO (2013) Every Newborn: An Action Plan to End Preventable Newborn Deaths. http://www.everynewborn.org/Documents/Every_Newborn_Action_Plan-ENGLISH_updated_July2014.pdf

[6] Aminu, M., Unkels, R., Mdegela, M., Utz, B., Adaji, S. and van den Broek, N. (2014) Causes of and Factors Associated with Stillbirth in Low- and Middle-Income Countries: A Systematic Literature Review. BJOG, 121, 141-153. http://dx.doi.org/10.1111/1471-0528.12995

[7] Di Mario, S., Say, L. and Lincetto, O. (2007) Risk Factors for Stillbirth in Developing Countries: A Systematic Review of the Literature. Sexually Transmitted Diseases, 34, S11-S21. http://dx.doi.org/10.1097/01.olq.0000258130.07476.e3

[8] Blencowe, H., Cousens, S., Jassir, F.B., et al., for The Lancet Stillbirth Epidemiology Investigator Group (2016) National, Regional, and Worldwide Estimates of Stillbirth Rates in 2015, with Trends from 2000: A Systematic Analysis. Lancet Global Health, 4, e98-e108. http://dx.doi.org/10.1016/S2214-109X(15)00275-2

[9] Suleiman, M.B. and Mokuolu, O.A. (2014) Perinatal Mortality in a Northwestern Nigerian City: A Wakeup Call. Frontiers in Paediatrics, 2, 105. http://dx.doi.org/10.3389/fped.2014.00105

[10] Fawole, A.O., Shah, A., Tongo, O., Dara, K., El-Ladan, A.M., Umezulike, A.C., et al. (2011) Determinants of Perinatal Mortality in Nigeria. International Journal of Gynecology and Obstetrics, 114, 37-42. http://dx.doi.org/10.1016/j.ijgo.2011.01.013

[11] National Population Commission (NPC) [Nigeria] and ICF International (2014) Nigeria Demographic and Health Survey 2013. NPC and ICF International, Abuja, Nigeria, and Rockville, Maryland, USA.

[12] Mohangoo, A.D., Blondel, B., Gissler, M., Velebil, P., Macfarlane, A., Zeitlin, J., and the Euro-Peristat Scientific Committee (2013) International Comparisons of Fetal and Neonatal Mortality Rates in High-Income Countries: Should Exclusion Thresholds Be Based on Birth Weight or Gestational Age? PLoS ONE, 8, e64869. http://dx.doi.org/10.1371/journal.pone.0064869

[13] Lee, A.C., Mullany, L.C., Tielsch, J.M., Katz, J., Khatry, S.K., LeClerq, S.C., Adhikari, R.K. and Darmstadt, G.L. (2011) Community-Based Stillbirth Rates and Risk Factors in Rural Sarlahi, Nepal. International Journal of Gynecology and Obstetrics, 113, 199-204. http://dx.doi.org/10.1016/j.ijgo.2010.12.015

[14] Lawn, J.E., Blencowe, H., Oza, S., et al., and the Lancet Every Newborn Study Group (2014) Every Newborn: Progress, Priorities, and Potential beyond Survival. Lancet, 384, 189-205. http://dx.doi.org/10.1016/S0140-6736(14)60496-7

[15] McClure, E.M., Pasha, O., Goudar, S.S., Chomba, E., Garces, A., Tshefu, A., et al. (2011) Epidemiology of Stillbirth in Low-Middle Income Countries: A Global Network Study. Acta Obstetricia et Gynecologica Scandinavica, 90, 13791385. http://dx.doi.org/10.1111/j.1600-0412.2011.01275.X

[16] Gilbert, N.L., Casapia, M., Joseph, S.A., Ryan, J.A. and Gyorkos, T.W. (2010) Inadequate Prenatal Care and the Risk of Stillbirth in the Peruvian Amazon. International Journal of Gynecology \& Obstetrics, 109, 155-156. http://dx.doi.org/10.1016/j.ijgo.2009.12.009

[17] Simkhada, B., van Teijlingen, E.R., Porter, M. and Simkhada, P. (2008) Factors Affecting the Utilization of Antenatal Care in Developing Countries: Systematic Review of the Literature. Journal of Advanced Nursing, 61, 244-260. http://dx.doi.org/10.1111/j.1365-2648.2007.04532.x

[18] Babalola, S. and Fatusi, A. (2009) Determinants of Use of Maternal Health Services in Nigeria—Looking beyond Individual and Household Factors. BMC Pregnancy and Childbirth, 9, 43. http://dx.doi.org/10.1186/1471-2393-9-43

[19] El Arifeen, S., Hill, K., Ahsan, K.Z., Jamil, K. and Streatfi, N.Q. (2014) Maternal Mortality in Bangladesh: A Countdown to 2015 Country Case Study. Lancet, 384, 1366-1374. http://dx.doi.org/10.1016/S0140-6736(14)60955-7

[20] Ibiebele, I., Coory, M., Boyle, F., Humphrey, M., Vlack, S. and Flenady, V. (2014) Stillbirth Rates among Indigenous and Non-Indigenous Women in Queensland, Australia: Is the Gap Closing? BJOG, 122, 1476-1483. http://dx.doi.org/10.1111/1471-0528.13047

[21] Thaddeus, S. and Maine, D. (1994) Too Far to Walk, Maternal Mortality in Context. Social Science \& Medicine, 38, 1091-1110. http://dx.doi.org/10.1016/0277-9536(94)90226-7

[22] Afnan-Holmes, H., Magoma, M., John, T., et al., the Tanzanian Countdown Country Case Study Group (2015) Tanza- 
nia’s Countdown to 2015: An Analysis of Two Decades of Progress and Gaps for Reproductive, Maternal, Newborn, and Child Health, to Inform Priorities for Post-2015. Lancet Global Health, 3, e396-e409.

http://dx.doi.org/10.1016/s2214-109x(15)00059-5

[23] Nouaili, E.B., Chaouachi, S., Ayadi, I., Said, A.B., Zouari, B. and Marrakchi, Z. (2010) Risk Factors for Perinatal Mortality in a Tunisian Population. International Journal of Gynecology \& Obstetrics, 111, 265-266. http://dx.doi.org/10.1016/j.ijgo.2010.07.009

[24] Olusanya, B.O., Afe, A.J. and Solanke, O.A. (2009) Are Risk Factors for Stillbirths in Low-Income Countries Associated with Sensorineural Hearing Loss in Survivors? The Journal of Maternal-Fetal \& Neonatal Medicine, 22, 576583. http://dx.doi.org/10.1080/14767050902906360

[25] Del Rosario, G.R., Lewis, T., Irons, B., Campbell-Forrester, S. and Weiss, H.L. (2004) Assessment of Risk Factors for Stillbirth among Pregnant Women in Jamaica. Journal of Obstetrics and Gynaecology, 24, 750-755. http://dx.doi.org/10.1080/014436104100009428

[26] Graner, S., Klingberg Allvin, M., Phuc, H.D., Krantz, G. and Mogren, I. (2009) The Panorama and Outcomes of Pregnancies within a Well-Defined Population in Rural Vietnam 1999-2004. International Journal of Behavioral Medicine, 16, 269-277. http://dx.doi.org/10.1007/s12529-008-9026-0

[27] Winter, R., Pullum, T., Florey, L. and Hodgins, S. (2014) Impact of Scale-Up of Maternal and Delivery Care on Reductions in Neonatal Mortality in USAID MCH Priority Countries, 2000-2010. DHS Analytical Studies No. 46, ICF International, Rockville, Maryland, USA.

[28] Metwally, M., Ong, K.J., Ledger, W.L. and Li, T.C. (2008) Does High Body Mass Index Increase the Risk of Miscarriage after Spontaneous and Assisted Conception? A Meta-Analysis of the Evidence. Fertility and Sterility, 90, 714726. http://dx.doi.org/10.1016/j.fertnstert.2007.07.1290

[29] Bellver, J., Melo, M.A., Bosch, E., Serra, V., Remohí, J. and Pellicer, A. (2007) Obesity and Poor Reproductive Outcome, the Potential Role of the Endometrium. Fertility and Sterility, 88, 446-451. http://dx.doi.org/10.1016/j.fertnstert.2006.11.162

[30] Clark, A.M., Thornley, B., Tomlinson, L., Gallet-ley, C. and Norman, R.J. (1998) Weight Loss in Obese Infertile Women Results in Improvement in Reproductive Outcome for All Forms of Fertility Treatment. Human Reproduction, 13, 1502-1505. http://dx.doi.org/10.1093/humrep/13.6.1502

[31] Ng, M., Fleming, T. and Robinson, M. (2014) Global, Regional, and National Prevalence of Overweight and Obesity in Children and Adults during 1980-2013: A Systematic Analysis for the Global Burden of Disease Study 2013. Lancet, 384, 766-781.

[32] De Lima Trindade, L., Amestoy, S.C., Picolo, D., Falchetti, G. and Milbrath, V.M. (2011) Fatores de riscoparamorte fetal no municipio de PatoBranco (Brasil) (Risk Factors for Fetal Death in the City of Pato Branco (Brazil)). Investigación y Educación en Enfermería, 29, 451-458.

[33] Saade, G.R., et al. (2011) Association between Stillbirth and Risk Factors Known at Pregnancy Confirmation the Stillbirth Collaborative Research Network Writing Group. The Stillbirth Collaborative Research Network Writing Group, JAMA, 306, 2469-2479. http://dx.doi.org/10.1001/jama.2011.1798

[34] Feresu, S.A., Harlow, S.D., Welch, K. and Gillespie, B.W. (2004) Incidence of and Socio-Demographic Risk Factors for Stillbirth, Preterm Birth and Low Birthweight among Zimbabwean Women. Paediatric and Perinatal Epidemiology Journal, 18, 154-163. http://dx.doi.org/10.1111/j.1365-3016.2003.00539.x

[35] Mondal, D., Galloway, T.S., Bailey, T.C. and Mathews, F. (2014) Elevated Risk of Stillbirth in Males, Systematic Review and Meta-Analysis of More than 30 Million Births. BMC Medicine, 12, 220. http://dx.doi.org/10.1186/s12916-014-0220-4

[36] Adimora, G.N. and Odetunde, I.O. (2007) Perinatal Mortality in University of Nigeria Teaching Hospital (UNTH) Enugu at the End of the Last Millennium. Nigerian Journal of Clinical Practice, 10, 19-23. 


\section{List of Abbreviations}

SSA: Sub Saharan Africa

SB: Stillbirth

ARR: Average Rate of Reduction

IRR: Incidence Risk Ratio

ENAP: Every Newborn Action Plan

ANC: Antenatal Care

EAs: Enumeration Areas

DHS: Demographic and Health Survey

SDGs: Sustainable Development Goals

FBD: Facility-Based Delivery

CS: Caesarean Section

BMI: Body Mass Index

\section{Warmly welcome your paper submission to OALib Journal!}

- Publication on a daily basis

- 9 subject areas of science, technology and medicine

- Fair and rigorous peer-review system

- Fast publication process

- Article promotion in various social networking sites (LinkedIn, Facebook, Twitter, etc.)

- Widely-targeted and multidisciplinary audience to read your research

Submit Your Paper Online: Click Here to Submit

Contact Us: service@oalib.com 